\title{
Thelypteris subg. Meniscium (Thelypteridaceae - Pterophyta) no Estado de São Paulo, Brasil
}

\author{
ALEXANDRE SALINO $^{1,3}$ e JOÃO SEMIR ${ }^{2}$
}

(recebido: 19 de janeiro de 2002; aceito: 6 de novembro de 2003)

\begin{abstract}
Thelypteris subg. Meniscium (Thelypteridaceae - Pterophyta) in the state of São Paulo, Brazil). This study presents results on the floristic survey of Thelypteris subg. Meniscium (Thelypteridaceae) in the state of São Paulo. Six species and one variety are recognized: T. angustifolia (Willd.) Proctor, T. chrysodioides (Fée) C.V. Morton var. goyazensis (Maxon \& C.V. Morton) C.V. Morton, T. longifolia (Desv.) R.M. Tryon, T. macrophylla (Kunze) C.V. Morton, T. maxoniana A.R. Sm., T. salzmannii (Fée) C.V. Morton, and T. serrata (Cav.) Alston. Descriptions for the subgenus and species, key for the species, as well as geographical distribution and comments are provided.
\end{abstract}

Key words - São Paulo, taxonomy, Thelypteridaceae, Thelypteris subg. Meniscium

RESUMO - (Thelypteris subg. Meniscium (Thelypteridaceae - Pterophyta) no Estado de São Paulo, Brasil). Este trabalho trata das espécies pertencentes a Thelypteris subg. Meniscium (Thelypteridaceae) no Estado de São Paulo. O grupo está representado no estado por seis espécies e uma variedade: T. angustifolia (Willd.) Proctor, T. chrysodioides (Fée) C.V. Morton var. goyazensis (Maxon \& C.V. Morton) C.V. Morton, T. longifolia (Desv.) R.M. Tryon, T. macrophylla (Kunze) C.V. Morton, T. maxoniana A.R. Sm., T. salzmannii (Fée) C.V. Morton e T. serrata (Cav.) Alston. São apresentadas descrições do subgênero e das espécies, chave de identificação para as espécies, bem como ilustrações, distribuição geográfica e comentários das espécies.

Palavras-chave - São Paulo, taxonomia, Thelypteridaceae, Thelypteris subg. Meniscium

\section{Introdução}

Thelypteridaceae Pic.Serm. é uma das maiores famílias de pteridófitas, com mais de 900 espécies, sendo a maioria de regiões tropicais e subtropicais, com menos de $2 \%$ ocorrendo nas regiões temperadas (Smith 1990). A classificação da família é controversa, havendo autores que reconheceram 32 gêneros (Pichi-Sermolli 1977), 25 gêneros (Holttum 1971), cinco gêneros (Smith 1990) e apenas um gênero (Tryon \& Tryon 1982). Além disso, há o arranjo utilizado por Smith (1992) no tratamento taxonômico da família para a Flora do Peru, no qual reconhece dois gêneros.

De acordo com Smith (1990, 1992, 1995a), o gênero Thelypteris Schmidel é subcosmopolita, com cerca de 875 espécies, das quais aproximadamente 300 ocorrem na região Neotropical (Smith 1992). Adotando-se o mesmo arranjo taxonômico proposto por Smith (1992), cinco subgêneros ocorrem no Brasil: Thelypteris subg.

\footnotetext{
1. Universidade Federal de Minas Gerais, Instituto de Ciências Biológicas, Departamento de Botânica, Caixa Postal 486, 30123-970 Belo Horizonte, MG, Brasil.

2. Universidade Estadual de Campinas, Instituto de Biologia, Departamento de Botânica, Caixa Postal 6109, 13083-970 Campinas, SP, Brasil.

3. Autor para correspondência: salino@icb.ufmg.br
}

Amauropelta (Kunze) A.R. Sm., T. subg. Cyclosorus (Link) C.V. Morton, T. subg. Goniopteris (C. Presl) Duek, T. subg. Meniscium (Schreber) C.F. Reed e T. subg. Steiropteris (C. Chr.) Iwats.

As espécies do subgênero Meniscium são facilmente reconhecidas pelo padrão de venação meniscióide e pela lâmina 1-pinada, com a pina apical semelhante às pinas laterais. $O$ padrão de venação meniscióide ocorre em poucas espécies do subgênero Goniopteris e em muitas espécies paleotropicais de Pronephrium C. Presl (Smith 1992). De acordo com Smith (1992), este padrão de venação evoluiu independentemente nos grupos de espécies do Velho e do Novo Mundo, mas é provavelmente uma indicação de forte afinidade entre os subgêneros Goniopteris e Meniscium.

Thelypteris subg. Meniscium compreende aproximadamente 20 espécies neotropicais (Smith 1992), das quais oito ocorrem no Brasil. Dentre as regiões mais ricas em espécies do subgênero Meniscium, o Peru é a mais representativa (16), seguido pelo Equador (12), a América Central (12), a Venezuela (nove) e o Brasil (oito).

Não existe uma revisão taxonômica atual do subgênero Meniscium, tendo sido tratado superficialmente por Christensen (1913) e Maxon \& Morton (1938). Posteriormente, as espécies de Thelypteris subg. Meniscium foram tratadas em 
trabalhos taxonômicos regionais, tais como para o México (Smith 1981a, Mickel \& Beitel 1988); Antilhas, Jamaíca e Porto Rico (Proctor 1977, 1985, 1989), América Central (Smith 1995a), Guatemala (Smith 1981b), Venezuela (Vareschi 1969, Smith 1995b), Equador (Smith 1983), Peru (Smith 1992), Guianas (Smith 1993), Argentina (Ponce 1987), Uruguai (Legrand 1952) e Santa Catarina, Brasil (Sehnem 1979). Há, ainda, uma sinopse das espécies brasileiras (Brade 1972).

Os trabalhos de Brade (1972) e Sehnem (1979) tratam superficialmente as espécies e estão desatualizados. Do Estado de São Paulo, o único estudo que apresenta descrições de espécies é o de Salino (1993) que conta com três espécies da região central do Estado.

Este trabalho é parte dos resultados do estudo da família Thelypteridaceae no Estado de São Paulo e são apresentados os resultados referentes a Thelypteris subg. Meniscium. Os resultados referentes ao gênero Macrothelypteris e a Thelypteris subg. Cyclosorus e T. subg. Steiropteris estão em Salino \& Semir (2002).

\section{Material e métodos}

O presente estudo foi realizado com base no exame de caracteres morfológicos, observações de populações no ambiente natural e em exsicatas de herbários nacionais e estrangeiros. O arranjo taxonômico utilizado para Thelypteris foi o de Smith (1992) e a apresentação dos táxons está em ordem alfabética.

Os sinônimos citados são aqueles considerados úteis para a região em questão, como os nomes usados na Flora Brasiliensis (Baker 1870), na Flora Catarinense (Sehnem 1979) e na sinopse de Brade (1972).

A descrição do subgênero foi feita com base em Smith (1992). As descrições das espécies foram feitas com base no material examinado do Estado de São Paulo, exceto quando este era escasso, caso em que o material adicional foi utilizado para complementação, principalmente o proveniente do Sudeste e Sul do país. As medidas dos diâmetros dos pecíolos foram feitas na base e das larguras das pinas na região mediana.

A distribuição geográfica das espécies no Brasil foi elaborada com base no material adicional examinado e nas informações encontradas na literatura. Citações de material adicional examinado podem ser encontradas em Salino (2000).

\section{Resultados e Discussão}

Thelypteris subg. Meniscium (Schreber) C.F. Reed, Phytologia 17:254. 1968. Meniscium Schreber, Gen. Pl. (Linn.) ed.8 (Schreber) 2:757. 1791.

Caule reptante, glabro a levemente escamoso. Lâmina geralmente pinada, raramente simples e inteira; pina apical igual às laterais, base não reduzida. Gemas geralmente ausentes, às vezes presentes na base das pinas proximais. Aeróforos ausentes. Indumento de tricomas simples, setiformes, às vezes arqueados; tricomas glandulares geralmente ausentes. Nervuras regularmente anastomosadas, com nervuras transversais formando aréolas regulares em 4-25 fileiras entre a costa e a margem, com uma vênula excurrente, geralmente as vênulas originam-se do ponto de união das nervuras transversais (venação meniscióide). Soros oblongos a lineares sobre as nervuras transversais, geralmente arqueados, às vezes retos; indúsio ausente; esporângios glabros ou com tricomas setiformes presentes na cápsula ou no pedicelo; esporos com rugas proeminentes, superfície papilada ou reticulada.

Nas regiões Centro-Oeste, Sudeste e Sul do Brasil ocorrem seis espécies e uma variedade de Thelypteris subg. Meniscium, sendo que todas foram encontradas no Estado de São Paulo. As seis espécies e a variedade estudadas apresentam ampla distribuição na região neotropical. Apesar disso, no Estado de São Paulo apresentam padrões de ocorrência distintos. Thelypteris longifolia, $T$. salzmannii e $T$. serrata ocorrem em diversas regiões do estado, tanto em áreas litorâneas quanto do interior, e são as espécies mais comuns. Enquanto T. angustifolia e $T$. chrysodioides ocorrem exclusivamente no interior, da região central em direção ao norte, nordeste e sudeste do estado, estando ausentes nas áreas das Serras do Mar e Mantiqueira e do litoral do estado. Já T. macrophylla e T. maxoniana ocorrem exclusivamente nas florestas da planície litorânea ou das encostas da Serra do Mar.

Comparando-se o conjunto de espécies ocorrente no Estado de São Paulo, com os dos outros estados da região Centro-oeste, Sudeste e Sul do Brasil, o Estado de São Paulo possui maior número de espécies em comum com Minas Gerais (seis), Goiás (seis) e Mato Grosso (seis), Rio de Janeiro (quatro) e Espírito Santo (quatro).

Chave para as espécies e variedade de Thelypteris subg. Meniscium do Estado de São Paulo

1. Tricomas setiformes presentes no pedicelo dos esporângios, aparecendo como tricomas entre os esporângios

2. Pinas lineares a estreito-elípticas; base das pinas proximais longamente cuneada; folhas monomorfas; soros não confluentes na maturidade . 3. T. longifolia 
2. Pinas largamente elípticas a lanceoladas; base das pinas proximais arredondada, curtamente cuneada ou oblíqua; folhas monomorfas a levemente dimorfas; soros às vezes confluentes na maturidade 2. T. chrysodioides var. goyazensis

1. Tricomas setiformes ausentes no pedicelo dos esporângios, ás vezes presentes na cápsula junto ao ânulo

3. Tricomas glandulares curto-pedicelados presentes em toda a face abaxial das pinas, às vezes apenas na costa 5. T. maxoniana

3. Tricomas glandulares ausentes em toda a face abaxial das pinas

4. Margens das pinas serreadas a uncinado-serreadas 7. T. serrata

4. Margens das pinas inteiras, crenadas ou crenuladas

5. Esporângios cobrindo toda a face abaxial da pina (soros acrosticóides), dispostos sobre as nervuras secundárias e no tecido laminar no interior das aréolas; folhas fortemente dimorfas, as estéreis com pinas em menor número, bem maiores e mais largas ... 4. T. macrophylla

5. Esporângios geralmente não cobrindo toda a face abaxial da pina, dispostos apenas sobre as nervuras secundárias, ausentes no tecido laminar no interior das aréolas, às vezes soros com aparência acrosticóide; folhas monomorfas ou levemente dimorfas, sendo as estéreis com pinas levemente maiores e mais largas

6. Pinas proximais com base cuneada ou oblíqua; face abaxial do tecido laminar glabra; esporângios às vezes com tricomas setiformes na cápsula próximo ao ânulo .... 1. T. angustifolia

6. Pinas proximais com base arredondada ou truncada, às vezes oblíqua; face abaxial do tecido laminar pubescente; esporângios glabros 6. T. salzmannii

1. Thelypteris angustifolia (Willd.) Proctor, Bull. Inst. Jamaica, Sci. Ser. 5:57. 1993. इ Meniscium angustifolium Willd., Sp. pl., ed. 4, 5:133. 1810. $\equiv$ Phegopteris angustifolia (Willd.) Mett., Filic. Lechl. 2:22. 1859. $\equiv$ Dryopteris angustifolia (Willd.) Urban, Symb. Antill. 4:21. 1903. Tipo: VENEZUELA: CARACAS: Bredemeyer s.n. (holótipo B, Herb. Willd. 19574, n.v.). Figuras 1A-B.

Caule curto a longo-reptante. Folhas levemente dimorfas, as férteis maiores, porém com pinas menores e mais estreitas; folhas estéreis $28-75 \mathrm{~cm}$ compr., pecíolo 12-28 cm compr. e 2-7 mm diâm., lâmina $16-47 \mathrm{~cm}$ compr. e pinas 7,5-17,5 × 0,9-2,7 cm; folhas férteis 34,5-105 cm compr., pecíolo $16-70 \mathrm{~cm}$ compr. e 2-7 mm diâm., lâmina 18,5-35 cm compr. e pinas 7,7-11 × 0,7-1,4 cm. Pecíolo glabrescente a moderadamente pubescente na face adaxial, com tricomas extremamente arqueados. Lâmina pinada, oval, com 5-10 pares de pinas. Raque glabra na face abaxial e glabrescente a moderadamente pubescente na face adaxial. Gemas ausentes. Pinas sésseis a curto pecioluladas (até $5 \mathrm{~mm}$ compr.), elípticas, com base cuneada, nas proximais cuneada ou oblíqua, margens inteiras nas pinas estéreis e geralmente crenuladas nas férteis, raramente inteiras, ápice acuminado; face adaxial esparsamente pubescente na costa; face abaxial glabrescente a esparsamente pubescente na costa e nervuras, e tecido laminar glabro; nervuras costais, 11-16 a cada $3 \mathrm{~cm}$; nervuras secundárias retas a levemente arqueadas nas pinas férteis e subsigmóides nas estéreis; 4-10(-13) fileiras de aréolas entre a costa e a margem. Indumento de tricomas arqueados, presente no pecíolo, na raque e em ambas as faces da costa; tricomas glandulares ausentes. Soros lineares, arqueados, dispostos apenas sobre as nervuras secundárias, subconfluentes na maturidade; esporângios glabros, ou às vezes com tricomas setiformes na cápsula junto ao ânulo.

Material examinado: BRASIL: São PaUlo: Botucatu, Rio do Peixe, IX-1906, G. Edwall 5011 (UC); Gália, Estação Ecológica de Caitetus, 14-VII-1994, A. Salino 1967 (BHCB, UC); idem, 14-VII-1994, A. Salino 1969 (BHCB, UC).

Thelypteris angustifolia distingüe-se das demais espécies do subgênero pelas pinas estreitas com base cuneada. Thelypteris maxoniana A.R. Sm. e T. longifolia (Desv.) R.M. Tryon também possuem as bases das pinas cuneadas, porém possuem esporângios com tricomas no pedicelo. Segundo Smith (1992), T. lancea A.R. Sm. (Peru e Bolívia) é a mais semelhante e provavelmente mais relacionada com $T$. angustifolia, da qual difere por possuir tricomas adpressos na face abaxial, pinas estéreis mais largas $(3,5 \mathrm{~cm})$, lanceoladas, com base arredondada ou truncada. Alguns exemplares de T. angustifolia parecem com alguns de T. salzmannii, mas esta espécie possui a base das pinas 

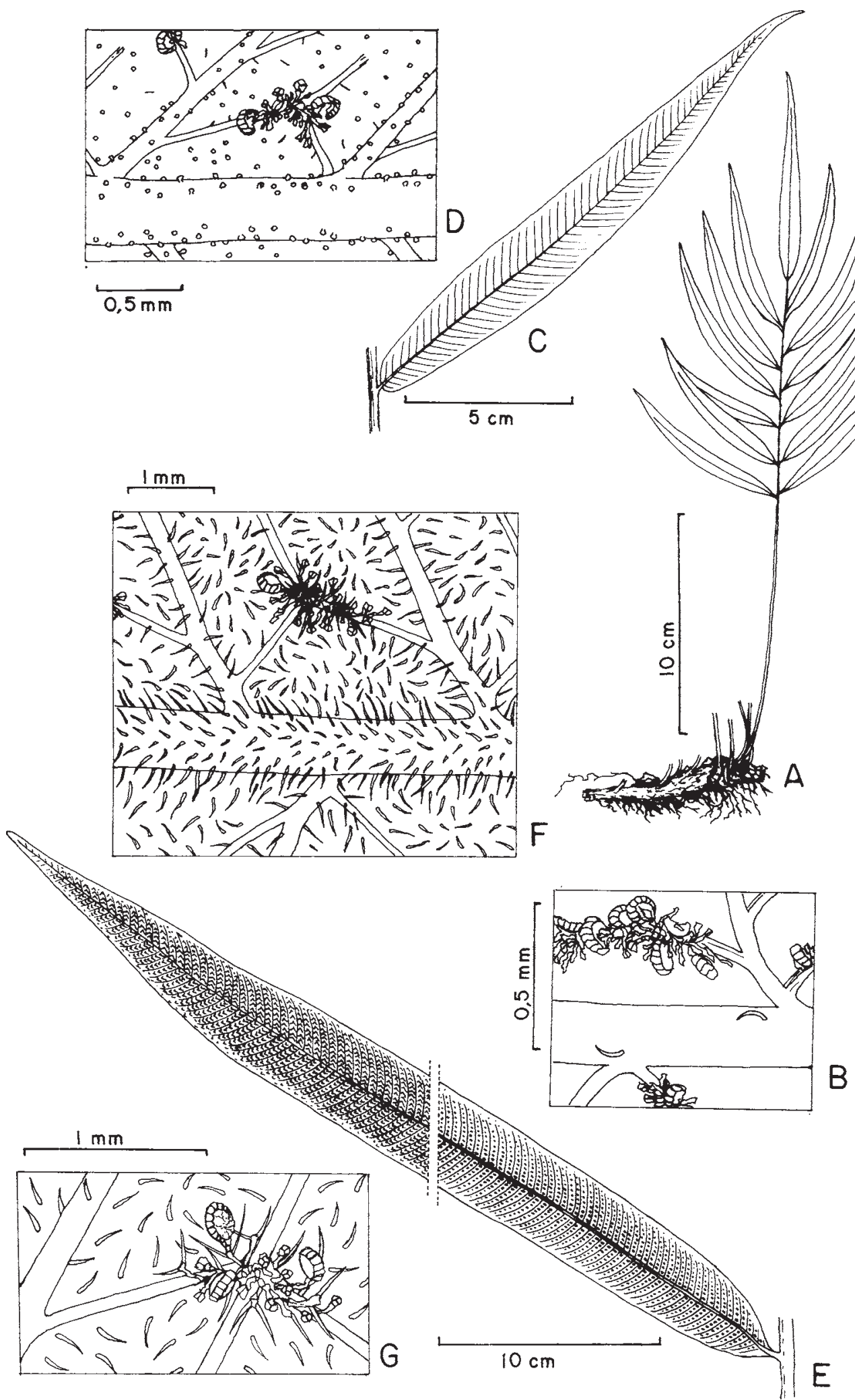

Figura 1. A-B. Thelypteris angustifolia. A. Hábito. B. Detalhe da face abaxial da pina, mostrando um soro e tricomas curvos da costa. C-D. Thelypteris maxoniana. C. Pina mediana. D. Detalhe da face abaxial da costa e nervuras, mostrando os tricomas glandulares. E-G. Thelypteris longifolia. E. Pina proximal. F. Detalhe da face abaxial da costa e nervuras, mostrando os tricomas setiformes e um soro. G. Detalhe de um soro mostrando os esporângios com tricomas no pedicelo (A: Salino 1967; B: Salino 1969; C-D: Salino 407; E: Salino 939; F-G: Salino 593). 
arredondadas ou truncadas e o tecido laminar pubescente na face abaxial.

Segundo Smith (1992), Thelypteris angustifolia ocorre nas Antilhas, sul do México até o Panamá, Colômbia e Venezuela até a Bolívia, Brasil e Paraguai. No Brasil ocorre nos estados de Goiás, Mato Grosso, Mato Grosso do Sul, Tocantins, Minas Gerais e São Paulo. Ocorre no interior de florestas úmidas, geralmente entre rochas úmidas no meio de riachos ou no solo às margens de riachos, geralmente em locais total a parcialmente sombreados, em altitudes de 550-650 m. No Estado de São Paulo, T. angustifolia foi encontrada apenas em florestas de galeria, na região de Botucatu e Gália.

2. Thelypteris chrysodioides (Fée) C.V. Morton var. goyazensis (Maxon \& C.V. Morton) C.V. Morton, Contr. U.S. Natl. Herb. 38:51. 1967. $\equiv$ Dryopteris chrysodioides (Fée) Maxon \& C.V. Morton var. goyazensis Maxon \& C.V. Morton, Bull. Torrey Bot. Club 65:374. 1938. Tipo: BRASIL: GoIÁs: Rio Corumbá, A. Glaziou 22631 (holótipo NY; isótipos F, UC).

$=$ Dryopteris handroi Brade, Arq. J. Bot. Rio de Janeiro 18:24. 1965. $\equiv$ Thelypteris handroi (Brade) C.F. Reed, Phytologia 17(4):281. 1968. $\equiv$ Meniscium handroi (Brade) Brade, Bradea 1(22):229. 1972. Tipo: BRASIL: São PAuLo: Moji-Guaçu, Reserva Florestal, 19-IX-1956, O. Handro 629 (holótipo SP; isótipos BHCB, SPF). Syn. nov.

Figuras 2A-D.

Caule curto-reptante. Folhas monomorfas a levemente dimorfas, as folhas férteis com pinas menores e mais estreitas; folhas estéreis 66-227 cm compr., pecíolo 31-117 cm compr. e 3,5-12 mm diâm., lâmina $35-110 \mathrm{~cm}$ compr. e pinas $22,5-40 \times 4,2-7 \mathrm{~cm}$; folhas férteis 115-200 cm compr., pecíolo 71-115 cm compr. e 4-10 mm diâm., lâmina 44-85 cm compr. e pinas 16,5-26 $\times 2,2-5,3 \mathrm{~cm}$. Pecíolo glabro ou glabrescente na face adaxial. Lâmina pinada, oval a lanceolada, com 3-10 pares de pinas. Raque glabrescente a moderadamente pubescente. Gemas ausentes. Pinas sésseis a curto pecioluladas (até $5 \mathrm{~mm}$ compr.), largamente elípticas a lanceoladas, com base arredondada, curtamente cuneada ou às vezes obliqua, nas proximais arredondada, curtamente cuneada ou oblíqua, margens sinuadas a fortemente crenadas, raramente inteiras, ápice acuminado a levemente caudado; face adaxial glabrescente a esparsamente pubescente, especialmente na costa, face abaxial esparsa a densamente pubescente; nervuras costais $6-12$ a cada $3 \mathrm{~cm}$; nervuras secundárias subsigmóides; 13-25 fileiras de aréolas entre a costa e a margem. Indumento de tricomas geralmente arqueados, presente na raque, em ambas as faces da costa, face adaxial das nervuras e tecido laminar, às vezes também no pecíolo; tricomas glandulares ausentes. Soros oblongos a lineares, levemente arqueados, dispostos apenas sobre as nervuras secundárias, às vezes confluentes na maturidade; esporângios com tricomas setiformes no pedicelo.

Material examinado: BRASIL: SÃo PaUlo: Casa Branca, 17-VI-1995, M.R. Pietrobom-da-Silva 2020 (BHCB, HB, MBM); Itirapina, Estação Ecológica do Instituto Florestal, Cerrado da Estrela, 21-VII-1991, A. Salino 959b (BHCB, UC, UEC); Moji-Guaçu, Reserva Florestal do Instituto de Botânica, 7-VI-1989, E.A. Simabukuro 3 (SJRP, UEC); idem, 12-VII-1989, E.A. Simabukuro 10 (UEC); idem, 27-IX-1989, E.A. Simabukuro 9 (UEC); idem, 27-IX-1989, E.A. Simabukuro 16 (UEC); idem, 11-X-1989, E.A. Simabukuro et al. 31 (UEC); idem, 16-IV-1993, E.A. Simabukuro 96 (BHCB); São Pedro, Alpes das Águas, 5-VIII-1994, K. D. Barreto et al. 2806 (BHCB, ESA).

Segundo Smith (1992), na venação, bem como na forma e tamanho dos soros, Thelypteris chrysodioides var. goyazensis é mais semelhante a T. membranacea (Mett.) R.M. Tryon, mas esta difere por ter tricomas adpressos na face abaxial da costa e do tecido laminar. Já Maxon \& Morton (1938) separam T. membranacea de $T$. chrysodioides var. goyazensis, por esta última possuir as pinas férteis menores que as estéreis e com as margens conspicuamente crenadas, bem como pelos soros confluentes. Maxon \& Morton (1938) reconheceram duas variedades para esta espécie, sendo que $T$. chrysodioides var. goyazensis difere da variedade típica pelas pinas estéreis maiores e em maior número e margens das pinas férteis fortemente crenadas.

Figure 1. A-B. Thelypteris angustifolia. A. Habit. B. Detail of the abaxial side of pinna, showing a sorus, and curved trichomes on costa. C-D. Thelypteris maxoniana. C. Middle pinnae. D. Detail of the abaxial side of costa and veins, showing glandular trichomes. E-G. Thelypteris longifolia. E. Proximal pinna. F. Detail of the abaxial side of costa and veins, showing setiform trichomes, and a sorus. G. Detail of sorus, showing the sporangia with setiform trichomes on pedicel (A: Salino 1967; B: Salino 1969; C-D: Salino 407; E: Salino 939; F-G: Salino 593). 

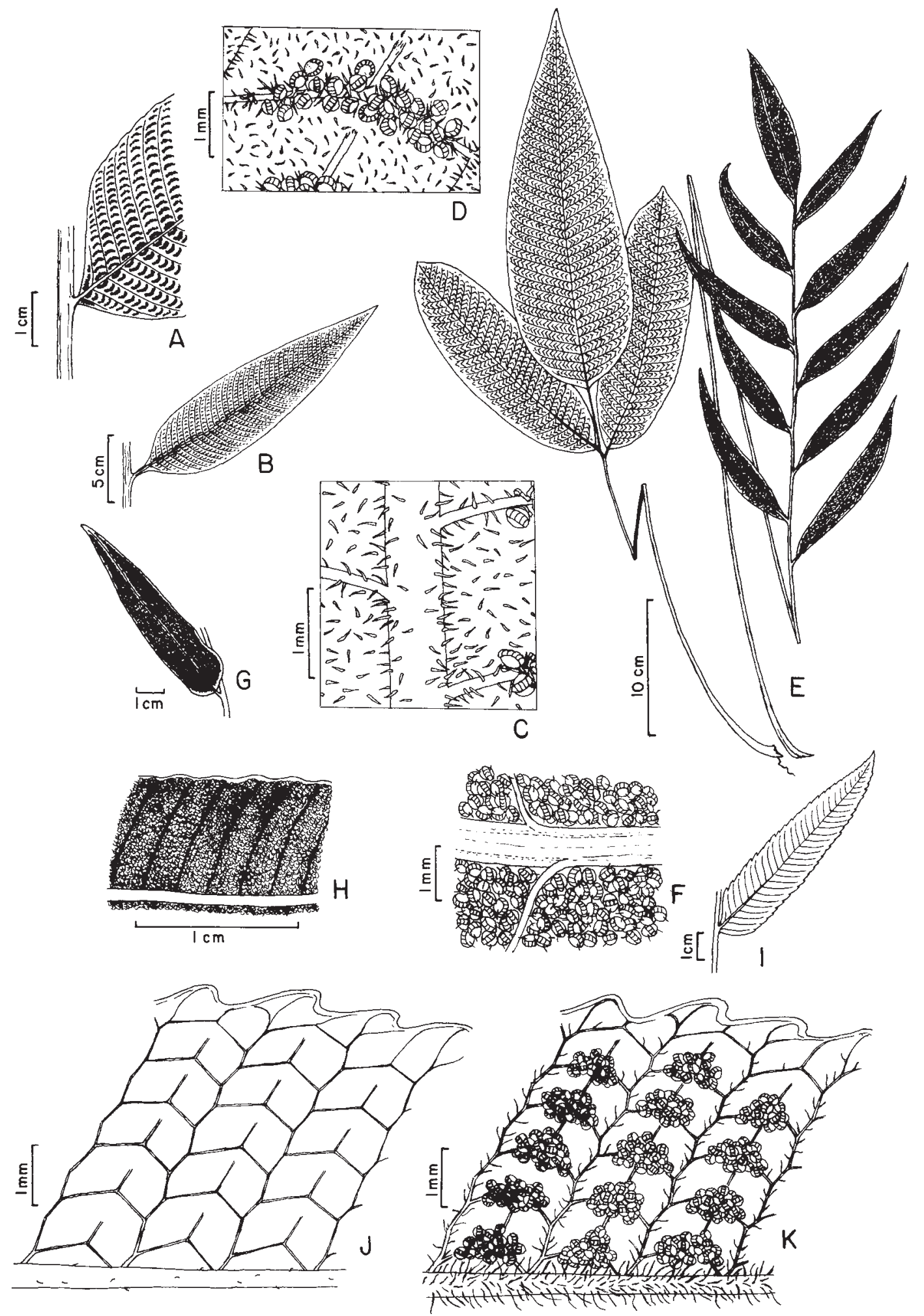

Figura 2. A-D. Thelypteris chrysodioides var. goyazensis. A. Porção basal de uma pina distal. B. Pina proximal. C. Detalhe da face abaxial de uma pina. D. Detalhe de um soro mostrando os tricomas entre os esporângios. E-F. Thelypteris macrophylla. E. Hábito, mostrando a folha fértil e a estéril. F. Detalhe dos esporângios, mostrando os tricomas setiformes presentes na cápsula. G-H. Thelypteris salzmannii. G. Pina mediana. H. Face abaxial de uma pina fértil, mostrando os soros confluentes na maturidade. I-K. Thelypteris serrata. I. Pina mediana. J. Detalhe da face adaxial da costa, nervuras e margem da pina. K. Detalhe da face abaxial da costa e nervuras, mostrando os tricomas setiformes e os soros (A-B: Barreto 2806; C-D: Simabukuro 96; E-F: Wacket 211; G-H: Salino 2103; I-K: Hoehne 3297). 
Thelypteris chrysodioides var. goyazensis possui o indumento da face abaxial das pinas semelhante ao de T. longifolia, esta, no entanto possui as pinas mais estreitamente elípticas e com o ápice longamente acuminado, bem como os soros estreitos e em menor número, nunca confluentes na maturidade.

Thelypteris chrysodioides var. goyazensis ocorre nas Guianas, Brasil, Equador até Bolívia (Smith 1992). No Brasil ocorre no Distrito Federal e em Goiás, Mato Grosso, Minas Gerais e São Paulo. Ocorre preferencialmente no interior de florestas ciliares e paludosas, às vezes nas bordas, de 500-800 $\mathrm{m}$ de altitude.

3. Thelypteris longifolia (Desv.) R.M. Tryon, Rhodora 69:777. 1967. $\equiv$ Meniscium longifolium Desv., Mem. Soc. Linn. Paris, 6:223. 1827. = Dryopteris reticulata var. longifolia (Desv.) Rosenst. in Buchtien, Contr. Fl. Bol. 1:44. 1910. Tipo: VENEZUELA: Sucre: A.V. Humboldt s.n. (holótipo B, n.v.).

Figuras 1E-G.

Caule curto-reptante. Folhas $95-226 \mathrm{~cm}$ compr., monomorfas. Pecíolo 41-125 cm compr., 5-9 mm diâm.; glabro ou grabrescente. Lâmina 50-150 cm compr., pinada, geralmente lanceolada, com (7-)11-18(-23) pares de pinas. Raque glabra a esparsamente pubescente. Gemas ausentes. Pinas 16-43 × 2-5,3 cm, sésseis, exceto as basais que são curta a longamente pecioluladas (3,5-13 mm compr.), lineares a estreitamente elípticas, com base oblíqua a longamente cuneada, as aproximais longamente cuneada, margens inteiras a crenadas, ápice longamente acuminado; face adaxial glabra a levemente pubescente na costa; face abaxial esparsa a moderadamente pubescente em toda a superfície; nervuras costais, $8-14(-17)$ a cada $3 \mathrm{~cm}$; nervuras secundárias levemente sigmóides; (5)8-15 fileiras de aréolas entre a costa e a margem. Indumento de tricomas setiformes, presentes na raque, na face adaxial da costa e em toda a face abaxial das pinas; tricomas glandulares ausentes. Soros lineares, levemente arqueados, dispostos apenas sobre as nervuras secundárias, nunca confluentes na maturidade; esporângios com 1-2 tricomas setiformes no pedicelo.

Material examinado: BRASIL: São PAULO: Brotas, 14-VII-1991, A. Salino 939 (BHCB, UEC); idem, fazenda Rochedo, 17-X-1991, A. Salino 1117 (BHCB, UEC); Iguape, Caiuvá, III-1928, A.C. Brade 8630 (HB); Itirapina, 21-VII-1991, A. Salino 963 (BHCB, UEC); Moji-Guaçu, fazenda Campininha, 15-VII-1960, G. Eiten \& L. Eiten 2126 (SP, US); Presidente Bernardes, Pirapozinho-Mirante do Paranapanema, 8-III-1996, M.R. Pietrobom da Silva 3072 (HB, MBM, SJRP); São Carlos, trilha da Natureza, 5-III1993, A. Colli 2 (UEC); São José dos Campos, Córrego da Ressaca, 28-III-1962, I. Mimura 341 (GH, US); São Sebastião - Bertioga, 10-XI-1976, P.E. Gibbs et al. 3531 (UEC); Serra de Paranapiacaba, XI-1925, A.C. Brade 21440 (HB); Ubatuba, Picinguaba, 13-XI-1993, A. Salino 1904 (BHCB).

Thelypteris longifolia é relacionada com T. maxoniana e T. arborescens (Willd.) C.V. Morton (América Central, Colômbia, Venezuela, Equador, Guianas e Brasil - região Amazônica). No entanto, T. maxoniana possui tricomas glandulares curtopedicelados e capitados, presentes em toda a face abaxial das pinas, raramente alguns tricomas simples e setiformes presentes na face abaxial da costa. Segundo Smith (1992), as diferenças entre $T$. arborescens e T. longifolia são desprezíveis e as duas talvez possam ser sinonimizadas. Segundo esse autor, as diferenças das duas são primariamente de tamanho, sendo que T. arborescens possui folhas e pinas menores. Alguns exemplares de Minas Gerais e do Paraná são transicionais entre $T$. longifolia e $T$. maxoniana, apresentando tricomas glandulares e tricomas simples na face abaxial das pinas, especialmente na costa. Smith (1983) já citava a ocorrência de formas transicionais no Brasil e na Colômbia. Uma futura reavaliação da delimitação exata destas três espécies é necessária.

Thelypteris longifolia ocorre na Venezuela, Colômbia, Equador, Bolívia e Brasil. No Brasil, ocorre no Distrito Federal e no Amazonas, Goiás, Mato Grosso,

Figure 2. A-D. Thelypteris chrysodioides var. goyazensis. A. Basal portion of a distal pinna. B. Proximal pinna. C. Detail of the abaxial side of pinna. D. Detail of a sorus, showing setiform trichomes rising between sporangia. E-F. Thelypteris macrophylla. E. Habit, showing fertile and sterile leaves. F. Detail of sporangia, showing setiform trichomes on capsule. G-H. Thelypteris salzmannii. G. Middle pinna. H. Abaxial side of the fertile pinna, showing confluent sori at maturity. I-K. Thelypteris serrata. I. Middle pinna. J. Detail of the adaxial side of costa, veins and pinna margin. K. Detail of the abaxial side of costa and veins, showing setiform trichomes and sori (A-B: Barreto 2806; C-D: Simabukuro 96; E-F: Wacket 211; G-H: Salino 2103; I-K: Hoehne 3297). 
Mato Grosso do Sul, Minas Gerais, Espírito Santo, Rio de Janeiro, São Paulo, Paraná e Santa Catarina. Ocorre às vezes em fendas de paredões rochosos úmidos, mas é mais comum em solos encharcados de florestas paludosas do interior do Estado e florestas úmidas da planície costeira, de 5-900 $\mathrm{m}$ de altitude.

4. Thelypteris macrophylla (Kunze) C.V. Morton, Amer. Fern J. 61:17. 1971. Meniscium macrophyllum Kunze, Flora 22(1):44. 1839. $\equiv$ Dryopteris macrophylla (Kunze) C. Chr., Index Fil. Suppl. 1:35. 1913. $\equiv$ Bolbitis macrophylla (Kunze) Maxon \& C.V. Morton, Bull. Torrey Bot. Club. 65:375. 1938. Tipo: BRASIL: BAHIA: Serra do Mar, near Ilhéos, C.F.P. Martius 363 (isótipo NY).

= Meniscium guyanense Fée, Gen. Fil.:224. 1852. Thelypteris guyanensis (Fée) C.V. Morton, Amer. Fern J. 61:19. 1971. Tipo: GUIANA FRANCESA: ad amnes Conana et Gaberet, Leprieur s.n. (holótipo P, n.v.). = Acrostichum fendleri Baker, J. Bot. 25:100. 1887. Tipo: TRINIDAD: Fendler 88 (holótipo K, n.v.; isótipos NY, UC, US).

Figuras 2E-F.

Caule curto-reptante. Folhas dimorfas, as folhas férteis com pecíolo maior e pinas mais numerosas e estreitas; folhas estéreis $27-117 \mathrm{~cm}$ compr., pecíolo 11-68 cm compr. e 1,3-6 mm diâm., lâmina 27,5-65 cm compr. e pinas $17,5-35 \times 5,5-8 \mathrm{~cm}$; folhas férteis $85-137 \mathrm{~cm}$ compr., pecíolo 46-84,5 cm compr. e 4,5-8,5 mm diâm., lâmina 23,5-67 cm compr. e pinas 12,5-17,5 × 2,3-3,8 cm. Pecíolo glabro ou glabrescente. Lâmina pinada, às vezes simples e inteira quando jovem, com contorno oblongo, com 1-10 pares de pinas. Raque esparsa a moderadamente pubescente. Gemas ausentes. Pinas sésseis a curto pecioluladas (até $6,5 \mathrm{~mm}$ compr.), elípticas a lanceoladas, com base arredondada a cuneada, margens sinuadas a fortemente crenadas, raramente inteiras, ápice agudo, acuminado ou levemente caudado; face adaxial glabrescente a esparsamente pubescente na costa e nervuras; face abaxial esparsa a densamente pubescente na costa e nervuras; nervuras costais, $5-12$ a cada $3 \mathrm{~cm}$; nervuras secundárias sigmóides nas estéreis e levemente arqueadas nas férteis; 13-25 aréolas entre a costa e a margem. Indumento de tricomas arqueados, presente na raque em ambas as faces da costa e nervuras; tricomas glandulares ausentes. Soros oblongos, dispostos sobre as nervuras e no tecido laminar entre as nervuras, confluentes na maturidade, muitas vezes cobrindo toda a face abaxial da pina; esporângios com tricomas setiformes na cápsula próximo ao ânulo, às vezes ausentes.
Material examinado: BRASIL: SÃo PaUlo: Serra do Mar, s.d. M. Wacket 211 (GH, NY, SPF).

Material adicional examinado: BRASIL: BAHIA: Uruçu, 7-V-1992, W.W. Thomas et al. 9207 (NY). Espírito Santo: Sooretama, Reserva Florestal de Linhares, 20-III-1999, A. Salino 4528 (BHCB, CVRD). Minas Gerais: Almenara, fazenda Limoeiro, Mata da Mamoneira, 23-II-2003, A. Salino 8307 (BHCB). Pernambuco: Timbaúba, Serra do Mascarenhas, 14-XII-2001, M.R. Pietrobom 5433 (BHCB, UFPE). Rio de JANeIro: Silva Jardim, Reserva Biológica de Poço das Antas, 13-I-1994, R. Guedes et al. 2342 (BHCB).

Thelypteris macrophylla é mais relacionada com T. chrysodioides pelo tamanho das pinas e aparência acrosticóide dos soros. No entanto, T. macrophylla possui as folhas claramente dimorfas, a face abaxial das pinas estéreis com indumento menos desenvolvido, inclusive com o tecido laminar glabro e esporângios presentes também no tecido laminar entre as nervuras secundárias. Já $T$. chrysodioides possui as folhas monomorfas a levemente dimorfas, o tecido laminar piloso em ambas as faces e esporângios restritos às nervuras secundárias. $\mathrm{O}$ material do Estado de São Paulo não possui tricomas setiformes na cápsula do esporângio, enquanto naquelas da Bahia, Pernambuco e de outros países, os tricomas podem estar presentes.

Thelypteris macrophylla ocorre em Trinidad e Tobago, Guianas, oeste da Venezuela, Equador, Peru e Brasil (Smith 1992). No Brasil ocorre na Bahia, Espírito Santo, Minas Gerais, Rio de Janeiro e São Paulo. Segundo Maxon \& Morton (1938), esta espécie também ocorre em Goiás, no entanto, todo material examinado parecido com T. macrophylla, proveniente de Goiás e Mato Grosso, pertence a $T$. chrysodioides.

No Estado de São Paulo, Thelypteris macrophylla é uma espécie rara, com apenas uma coleta proveniente da Serra do Mar. No Espírito Santo e em Minas Gerais, ocorre no interior de florestas periodicamente alagadas. É provável que no Estado de São Paulo, T. macrophylla também ocorra em florestas periodicamente inundadas existentes no litoral.

5. Thelypteris maxoniana A.R. Sm., Fieldiana, Bot., n.s. 29:71. 1992. Tipo: PERU: MAYNAs: Quistococha, vicinity of Iquitos, A. Gentry 20751 (holótipo MO, n.v.; isótipo UC).

= Dryopteris desvauxii Mett. f. glandulosa Maxon \& C.V. Morton, Bull. Torrey Bot. Club 65:372. 1938. $\equiv$ Thelypteris longifolia (Desv.) R.M. Tryon f. 
glandulosa (Maxon \& C.V. Morton) C.V. Morton, Contr. U.S. Natl. Herb. 38:52. 1967. Tipo: BRASIL: São Paulo: Morro das Pedras, A.C. Brade 5753 (holótipo NY).

Figuras 1C-D.

Caule curto-reptante. Folhas 72,5-242 cm compr., monomorfas. Pecíolo 27,5-97 cm compr., 5-12 mm diâm., glabro. Lâmina 45-145 cm compr., pinada, lanceolada, com 13-30 pares de pinas. Raque glabra. Gemas ausentes. Pinas 13-41 × 2-4,2 cm, sésseis, exceto as basais que são curta a longamente pecioluladas (até $8 \mathrm{~mm}$ compr.), estreitamente elípticas, com base oblíqua a longamente cuneada, margens crenadas a crenuladas, raramente inteiras ou sinuadas, ápice acuminado; face adaxial glabra; face abaxial glandulosa, raramente pubescente; nervuras costais, $9-14$ a cada $3 \mathrm{~cm}$; nervuras secundárias geralmente arqueadas a sigmóides; (5-)8-5 fileiras de aréolas entre a costa e a margem. Indumento de tricomas setiformes ausente em toda face abaxial, raramente presente na face abaxial da costa; tricomas glandulares, curto-pedicelados, presentes em toda face abaxial das pinas, às vezes apenas na costa. Soros lineares, arqueados, dispostos apenas sobre as nervuras secundárias, não confluentes na maturidade; esporângios glabros ou com tricomas glandulares no pedicelo.

Material examinado: BRASIL: São PAUlo: Cananéia, 17-II-1965, G. Eiten 6175-A (US); Iguape, Morro das Pedras, II-1928, A.C. Brade 5153 (UC); Pariquera-Açu, Pariquera-Mirim, Rio Ribeira, XI-1910, A.C. Brade 5053 (HB, SP); Santo André, Estação Rio Grande, s.d., M. Wacket 82 (SP); São Vicente, VI-1912, H. Luederwaldt s.n. (SP, SPF).

Thelypteris maxoniana é bastante semelhante a T. longifolia, que não possui tricomas glandulares na face abaxial das pinas, porém possui tricomas setiformes em toda a face abaxial das pinas. Já T. maxoniana possui tricomas glandulares, curto-pedicelados em toda a face abaxial das pinas, às vezes apenas na costa $\mathrm{e}$ raramente apresenta tricomas setiformes na costa. A ocorrência de tricomas glandulares no subgênero Meniscium é exclusiva desta espécie.

Thelypteris maxoniana ocorre na Colômbia, Bolívia e Brasil (Smith 1992). No Brasil, ocorre no Distrito Federal e em Goiás, Mato Grosso, Mato Grosso do Sul, São Paulo e Paraná. No Estado de São Paulo ocorre apenas nas florestas do litoral centro-sul e na Serra do Mar, onde cresce geralmente no solo, às vezes entre rochas, geralmente às margens de riachos, barrancos úmidos, de 5-800 $\mathrm{m}$ de altitude.
6. Thelypteris salzmannii (Fée) C.V. Morton, Los Angeles County Mus. Contr. Sci. 35:7. 1960. $\equiv$ Meniscium salzmannii Fée, Gen. Fil.:223. 1852. $\equiv$ Dryopteris salzmannii (Fée) Maxon \& C.V. Morton, Bull. Torrey Bot. Club 65:357. 1938. Tipo: BRASIL: BAHIA: Salzmann s.n. (isótipo NY; foto do holótipo NY). Figuras 2G-H.

Caule curto-reptante. Folhas levemente dimorfas, as férteis levemente maiores; folhas estéreis $39-131 \mathrm{~cm}$ compr., pecíolo 16-74 cm compr. e 4-7,5 mm diâm., lâmina 23-68 cm compr. e pinas 7,3-18 × 1,3-3,1 cm, folhas férteis $52-164 \mathrm{~cm}$ compr., pecíolo $23-84 \mathrm{~cm}$ compr. e 3,5-9 mm diâm., lâmina 29-80 cm compr. e pinas 11,4-22,5 × 1,3-4,1 cm. Pecíolo grabrescente a glabro. Lâmina pinada, lanceolada, com 6-12 pares de pinas. Raque glabrescente na face abaxial e esparsamente pubescente na face adaxial. Gemas ausentes ou presentes na base das pinas proximais. Pinas sésseis a curto pecioluladas (até $4 \mathrm{~mm}$ compr.), elípticas, com base arredondada a truncada, nas proximais, às vezes oblíquas, margens geralmente inteiras a levemente crenadas ou crenuladas, ápice geralmente acuminado, raramente agudo; face adaxial glabra ou glabrescente; face abaxial glabrescente a esparsamente pubescente, especialmente nas pinas férteis; nervuras costais, 9-25 a cada $3 \mathrm{~cm}$; nervuras secundárias arqueadas nas pinas férteis e sigmóides nas estéreis; 7-17 aréolas entre a costa e a margem. Indumento de tricomas arqueados, presente na face abaxial da costa, nervuras e tecido laminar, às vezes na face adaxial da costa; tricomas glandulares ausentes. Soros oblongos, arqueados, dispostos apenas sobre as nervuras secundárias, confluentes na maturidade; esporângios glabros.

Material examinado: BRASIL: São Paulo: Analândia, Serra do Cuscuzeiro, 1-IV-1988, A. Salino 430 (SJRP, UC); Assis, próximo à Represa do Cervo, 7-IV-1995, A. Salino 2100 (BHCB, UC); Brotas, mata de brejo junto ao Horto Municipal, 14-VII-1991, A. Salino 949 (BHCB, UEC); Casa Branca, 17-VI-1995, M.R. Pietrobom-da-Silva 2025 (HB); Itirapina, Serra do Itaqueri, 10-I-1992, A. Salino 1247 (BHCB, UEC); idem, Reserva do Instituto Florestal, Cerrado do Pedregulho, I-1997, A. Begovacz 51 (BHCB, SP); José Bonifácio, 18-X-1991, M.R. Pietrobom-da-Silva 5 (SJRP, SPF); Mirante do Paranapanema, rodovia Pirapozinho - Mirante do Paranapanema, 8-III-1996, M.R. Pietrobom-da-Silva 3121 (BHCB, HB, MBM); Moji-Guaçu, fazenda Campininha, 18-XII-1959, G. Eiten \& L. Eiten 1645 (GH, NY, SP, US); Piraçununga, junto ao rio do Roque, 
7-IX-1987, A. Salino 116 (BHCB); Presidente Bernardes, Rodovia Pirapozinho - Mirante do Paranapanema, 8-III-1996, M.R. Pietrobom-da-Silva 3076 (HB, MBM); Salesópolis, Estação Experimental de Boracéia, 8-13-II-1959, L. Travassos 25 (RB); São Paulo, Mooca, VII-1912, A.C. Brade 5286 (HB); São Simão, 29-II-1940, A.P. Viegas s.n. (IAC, RB); São Vicente, 26-XII-1954, W. Hoehne 4107 (BHCB, SJRP, $\mathrm{SPF})$; Ubatuba, próximo a Base Norte do Instituto Oceanográfico, VII-1960, I. Válio 111 (SP, SPF); idem, Parque Estadual da Ilha Anchieta, 6-II-1996, A. Salino 2548 (BHCB); Urupês, Rod. Roberto Mario Porosa, 7-IX-1992, C.E. Rodrigues \& M.R. Pietrobom-daSilva 176 (SJRP).

Maxon \& Morton (1938) sugerem que Thelypteris salzmannii seja relacionada a $T$. serrata, porém Smith (1983) acredita que seja mais relacionada com T. angustifolia. Estas três espécies possuem os esporângios glabros, porém $T$. angustifolia possui a base das pinas cuneada e $T$. serrata apresenta as pinas com margens serreadas a uncinado-serreadas, pelo menos no terço superior. Já $T$. salzmannii possui a base das pinas arredondada ou truncada e as margens das pinas inteiras, crenadas ou crenuladas.

Alguns exemplares maiores de Thelypteris salzmannii, têm sido identificados como $T$. reticulata (L.) Proctor, que é uma espécie com distribuição geográfica restrita à Flórida, sul do México, Antilhas, América Central, Colômbia e Venezuela.

Thelypteris salzmannii ocorre na Venezuela, Colômbia até Brasil e Bolívia (Smith 1992). No Brasil, ocorre no Distrito Federal e no Maranhão, Roraima, Bahia, Goiás, Mato Grosso, Minas Gerais, Rio de Janeiro, São Paulo e Paraná. É bastante comum no Estado de São Paulo, sendo geralmente encontrada em áreas abertas úmidas, freqüentemente em áreas paludosas, formando populações com muitos indivíduos agregados, de 5-850 m de altitude.

7. Thelypteris serrata (Cav.) Alston, Kew Bull. 1932:309. 1932. $\equiv$ Meniscium serratum Cav., Descr. P1.:548. 1802. $\equiv$ Dryopteris serrata (Cav.) C. Chr., Ind. Fil.:291. 1905. Tipo: CUBA: HavanA: Guio s.n. (holótipo MA, n.v.).

Figuras 2I-K.

Caule longo-reptante. Folhas 30-240 cm compr.; monomorfas a levemente dimorfas, as férteis com pinas mais estreitas; folhas estéreis $30-220 \mathrm{~cm}$ compr., pecíolo 12-100 cm compr. e 4-6 mm diâm., lâmina 18,5-120 cm compr. e pinas 4,5-26 × 1,1-3,3 cm; folhas férteis
50-240 cm compr. pecíolo 31-112 cm compr. e 4-7 mm diâm., lâmina $18,5-137 \mathrm{~cm}$ compr. e pinas 4,3-32 × 0,9-4,3 cm. Pecíolo glabrescente a pubescente. Lâmina pinada, lanceolada, com 9-22 pares de pinas gradualmente reduzidas em direção ao ápice. Raque glabrescente a esparsamente pubescente, especialmente na face adaxial. Gemas geralmente ausentes, às vezes presentes nas pinas proximais. Pinas sésseis a longamente pecioluladas (até $9 \mathrm{~mm}$ compr.), elípticas a lanceoladas, com base arredondada, truncada ou levemente cuneada, margens leve a fortemente serreadas ou uncinado-serreadas; ápice geralmente agudo; face adaxial glabra, exceto a costa, que é esparsa a moderadamente pubescente; face abaxial esparsa a moderadamente pubescente, especialmente na costa, nervuras costais e tecido laminar, esta última parte às vezes glabra; nervuras costais, $8-20$ a cada $3 \mathrm{~cm}$; nervuras secundárias levemente curvas a arqueadas nas pinas férteis e levemente sigmóides nas estéreis; 5-19 aréolas entre a costa e a margem. Indumento de tricomas eretos a arqueados, presente em ambas as faces da costa e face abaxial das nervuras costais e tecido laminar; tricomas glandulares ausentes. Soros oblongos a lineares, levemente curvos a arqueados, dispostos apenas sobre as nervuras secundárias, muitas vezes confluentes na maturidade; esporângios glabros.

Material examinado: BRASIL: SÃo PAULO: Américo de Campos, 4-IV-1995, M.R. Silva 1703 (SPF); Analândia, Serra do Cuscuzeiro, VI-1993, A. Salino s.n. (BHCB 29986, UC); Aparecida d'Oeste, rodovia Aparecida d'Oeste-Santa Fé do Sul, sítio São José, 4-IV-1995, M.R. Silva 1734 (HB, SJRP, SPF); Campinas, Joaquim Egídio, fazenda Riqueza, 6-XI-1938, A.P. Viegas s.n. (IAC, RB); Cosmorama, 4-IV-1995, M.R. Silva 1714 (HB, SJRP); Cubatão, 1906(5), M. Wacket 96 (NY, UC); Gália, Estação Ecológica de Caetetus, 14-VII-1994, A. Salino 1977 (BHCB); Iguape, Morro das Pedras, VII-1917, A.C. Brade 7700 (HB); idem, Morro das Pedras, 1921, A.C. Brade s.n. (NY, UC); Itanhaém, Vila Atlântica, 26-V-1950, A.B. Joly 1198 (BHCB, RB, SPF); Irapuã, córrego Figueira, 3-IV-1993, M.R. Silva 783 (HB); Itirapina, Reserva do Instituto Florestal, Cerrado do Pedregulho, IV-1997, A. Begovacz 55 (BHCB, SP); Jaci, Fazenda Remanso, 12-IX-1992, M.R. Silva 376 (HB, SPF); Jales, Pastos do retiro, 17-I-1950, W. Hoehne 3297 (BHCB, SPF); idem, 4-IV-1995, M.R. Silva 1725 (HB, SJRP, SPF); Monte Aprazivel, fazenda Água Limpa, 13-VI-1992, M.R. Silva 95 (SJRP); Monte Alto, Serra Anhumas, 3-VI-1995, M.R. Pietrobom-da-Silva 1807 (HB, MBM, SJRP); Mirassol, Instituto Penal Agrícola, 
Estação Biológica, 25-IV-1996, M.R. Pietrobom-daSilva 3246 (HB); Nova Aliança, Distrito de Nova Itapirema, Monte Belo, 11-VI-1992, M.R. Silva 158 (HB); Nova Itapirema, 27-VIII-1988, F.R. Sossae 47 (UC); Onda Verde, 11-IV-1996, M.R. Pietrobom-daSilva 3207 (HB); Potirendaba, 17-XII-1988, F.R. Sossae 72 (SJRP); Presidente Epitácio, margens do rio Paranapanema, área da Reserva Florestal Morro do Diabo, 9-11-IX-1985, P.G. Windisch 4253 (HB); Sales, estância Rodeio, 21-II-1993, M.R. Silva 733 (SPF); São José do Rio Preto, Estação Ecológica, Instituto Penal Agrícola, 10-III-1995, M.R. Pietrobom-da-Silva 2221 et al. (HB, SJRP); São Vicente, 25-II-1929, A.C. Smith 2008 (GH, US); Sete Barras, fazenda Intervales, Base de Saibadela, 21-VII-1994, A. Salino 2053 (BHCB); Sud Menuci, sítio Santa Helena, 10-X-1992, M.R. Silva 486 (HB); Teodoro Sampaio, Parque Estadual do Morro do Diabo, 17-I-1995, M.R. Silva 1611 (SJRP); Ubatuba, Parque Estadual da Ilha Anchieta, 8-V-1993, A. Salino 1734 (BHCB, UC); idem, Picinguaba, Casa da Farinha, 30-I-1996, A. Salino 2444 (BHCB).

Thelypteris serrata distingüe-se das demais espécies ocorrentes no Brasil pelas pinas com margens serreadas a uncinado-serreadas, pelo menos no terço superior. Essa característica também é encontrada em T. consobrina (Maxon \& C.V. Morton) R.M. Tryon (endêmica do Peru). Porém, T. consobrina possui as pinas distais não reduzidas, pinas oblongas, com ápice acuminado a caudado, a maioria das pinas são sésseis, exceto as proximais que são semi-adnatas a decorrentes; nervuras e tecido laminar glabros (Maxon \& Morton 1938, Smith 1992). Já T. serrata possui as pinas distais reduzidas, pinas lanceoladas ou elípticas, com ápice agudo, a maioria das pinas curto-pecioluladas, exceto as proximais que são sésseis e nervuras e tecido laminar pubescentes.

Alguns exemplares de Thelypteris serrata parecem muito, no aspecto geral, com T. salzmannii e T. chrysodioides, porém, as margens das pinas dessas espécies não são serreadas ou uncinado-serreadas, podendo ser inteiras, crenadas ou crenuladas. Além disso, T. chrysodioides possui tricomas no pedicelo dos esporângios.

Thelypteris serrata ocorre na Flórida, Antilhas, México até o Panamá, Colômbia até Guianas e Bolívia, Brasil, norte da Argentina e Paraguai (Smith 1992). Thelypteris serrata é a espécie do subg. Meniscium que apresenta a distribuição mais ampla no Brasil, ocorrendo no Amazonas, Amapá, Acre, Pará, Maranhão, Rondônia, Ceará, Paraíba, Bahia, Goiás, Mato Grosso, Mato Grosso do Sul, Minas Gerais,
Espírito Santo, Rio de Janeiro, São Paulo, Paraná, Santa Catarina e Rio Grande do Sul. Esta espécie também é a mais comum e abundante no Estado de São Paulo, onde ocorre preferencialmente em áreas abertas e brejosas, podendo ocorrer ao longo de riachos, no interior de florestas ciliares e paludosas, de 5-850 $\mathrm{m}$ de altitude.

Agradecimentos - Este trabalho é parte da tese doutorado de A. Salino, desenvolvida no Departamento de Botânica da Universidade Estadual de Campinas. À Capes pela concessão de bolsa de Doutorado (PICDT) para a realização deste estudo. Aos curadores dos herbários pelos empréstimos dos materiais estudados. Ao Dr. Alan R. Smith pela orientação em parte deste estudo. À bióloga Myrian Morato Duarte pela elaboração das ilustrações. Aos revisores do manuscrito pelas críticas e sugestões.

\section{Referências bibliográficas}

BAKER, J.G. 1870. Cyatheaceae et Polypodiaceae. In Flora Brasiliensis (C.F.P. Martius \& A.G. Eichler, eds.). F. Fleischer, Lipsiae, v.1, p.306-624.

BRADE, A.C. 1972. O gênero Dryopteris (Pteridophyta) no Brasil e sua divisão taxonômica. Bradea 1:191-261.

CHRISTENSEN, C. 1913. A monograph of the genus Dryopteris, Part I, the tropical American pinnatifidbipinnatifid species. Kongelige Danske Videnskabernes Selskabs Skrifter Naturdidenskabeliger og Mathematisk Afdeling 10:55-282.

HOLTTUM, R.E. 1971. Studies in the family Thelypteridaceae III. A new system of genera in the Old World. Blumea 19:17-52.

KRAMER, K.U. 1978. The pteridophytes of Suriname. Uitgaven Natuurwetenschappelijke Studiekring voor Suriname en de Nederlandse Antillen 93:1-198.

LEGRAND, D. 1952. Las especies de Dryopteris del Uruguay. Comunicaciones Botánicas del Museo de Historia Natural de Montevideo 2:1-27.

MAXON, W.R. \& MORTON, C.V. 1938. The American species of Dryopteris subgenus Meniscium. Bulletin of the Torrey Botanical Club 65:347-376.

MICKEL, J.T. \& BEITEL, J.M.. 1988. Pteridophyte Flora of Oaxaca, Mexico. Memoirs of the New York Botanical Garden 46:1-568.

PICHI-SERMOLLI, R.E.G. 1977. Tentamen pteridophytorum genera in taxonomicum ordinem redigendi. Webbia 31:313-512.

PONCE, M.M. 1987. Revision de las Thelypteridaceae (Pteridophyta) Argentinas. Darwiniana 28:317-390.

PROCTOR, G.R. 1977. Pteridophyta. In Flora of Lesser Antilles, Leeward and Windward Islands (R.A. Howard, ed.). Harvard University, Massachusetts. v.2, p.1-414. 
PROCTOR, G.R. 1985. Ferns of Jamaica. British Museum (Natural History), London.

PROCTOR, G.R. 1989. Ferns of Puerto Rico and the Virgin Islands. Memoirs of the New York Botanical Garden 53:1-389.

SALINO, A. 1993. Flora pteridofítica das matas ciliares da bacia do rio Jacaré-Pepira, Estado de São Paulo, Brasil. Dissertação de mestrado, Universidade Estadual de Campinas, Campinas.

SALINO, A. 2000. Estudos taxonômicos na família Thelypteridaceae (Polypodiopsida) no Estado de São Paulo, Brasil. Tese de doutorado, Universidade Estadual de Campinas, Campinas.

SALINO, A. \& SEMIR, J. 2002. Thelypteridaceae (Polypodiophyta) do Estado de São Paulo: Macrothelypteris e Thelypteris subgêneros Cyclosorus e Steiropteris. Lundiana 3:9-27.

SEHNEM, A. 1979. Aspidiáceas. In Flora Ilustrada Catarinense (R. Reitz, ed.). Herbário Barbosa Rodrigues, Itajaí.

SMITH, A.R. 1981a. Flora of Chiapas. Part 2. Pteridophytes. California Academy of Science, San Francisco.

SMITH, A.R. 1981b. The genus Thelypteris. In Fern and fern allies of Guatemala. Part II. Polypodiaceae (R.G. Stolze, ed.). Fieldiana, Botany, new series, 6:473-514.
SMITH, A.R. 1983. Flora of Ecuador. Polypodiaceae Thelypteridoideae. In Flora of Ecuador (G. Harling \& B. Sparre, eds.) 18:18-148.

SMITH, A.R. 1990. Thelypteridaceae. In The Families and genera of vascular plants (K.U. Kramer \& P.S. Green, eds.). Pteridophytes and Gymnosperms. Springer-Verlag, New York, v.1, p.263-272.

SMITH, A.R. 1992. Thelypteridaceae. In Pteridophyta of Peru. Part III (R.M. Tryon \& R.G. Stolze, eds.). Fieldiana, Botany, new series, 29:1-80.

SMITH, A.R. 1993. Thelypteridaceae. In Flora of the Guianas (A.R.A. Görts-Van Rijn, ed.). Koeltz Scientific Books, Königstein, p.77-115.

SMITH, A.R. 1995a. Thelypteridaceae. In Flora Mesoamericana. Psilotaceae a Salviniaceae (G. Davidse, M. Souza \& S. Knapp, eds.). Universidad Nacional Autónoma de México, México, v.1, p.164-195.

SMITH, A. R. 1995b. Thelypteridaceae. In Flora of the Venezuelan Guayana (P.E. Berry, B.K. Holst \& K. Yatskievych, eds.). Pteridophytes and Spermatophytes (AcanthaceaeAraceae). Timber Press, Portland, v.2., p.325-326.

TRYON, R.M. \& TRYON, A.F. 1982. Fern and allied plants, with special reference to tropical America. SpringerVerlag, New York.

VARESCHI, V. 1969. Helechos. In Flora de Venezuela (T. Lasser, ed.). Instituto Botánico, Caracas, v.1, tomo 2, p.473-1033. 